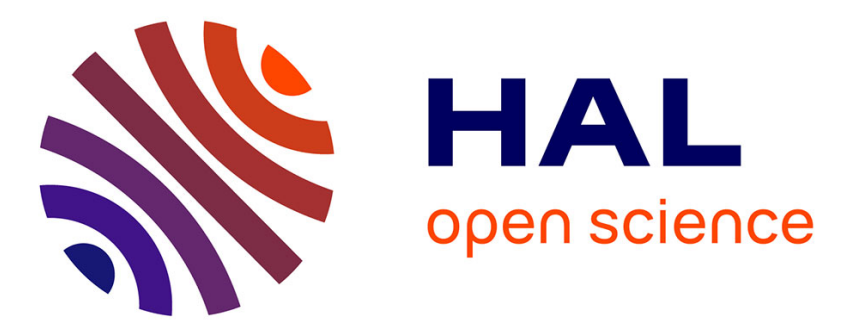

\title{
Harnessing Reversible Electronic Energy Transfer: From Molecular Dyads to Molecular Machines
}

\author{
Sergey A. Denisov, Shinlin Yu, Jean-Luc Pozzo, Gediminas Jonusauskas, \\ Nathan D. Mcclenaghan
}

\section{- To cite this version:}

Sergey A. Denisov, Shinlin Yu, Jean-Luc Pozzo, Gediminas Jonusauskas, Nathan D. Mcclenaghan. Harnessing Reversible Electronic Energy Transfer: From Molecular Dyads to Molecular Machines. ChemPhysChem, 2016, Molecular machines, 17 (12), pp.1794-1804. 10.1002/cphc.201600137 . hal01391653

\section{HAL Id: hal-01391653 \\ https://hal.science/hal-01391653}

Submitted on 17 Jan 2018

HAL is a multi-disciplinary open access archive for the deposit and dissemination of scientific research documents, whether they are published or not. The documents may come from teaching and research institutions in France or abroad, or from public or private research centers.
L'archive ouverte pluridisciplinaire HAL, est destinée au dépôt et à la diffusion de documents scientifiques de niveau recherche, publiés ou non, émanant des établissements d'enseignement et de recherche français ou étrangers, des laboratoires publics ou privés.

\section{(ㅇ)(1) $\$$}

Distributed under a Creative Commons Attribution - NonCommercial| 4.0 International 


\title{
Harnessing Reversible Electronic Energy Transfer: From Molecular Dyads to Molecular Machines
}

\author{
Sergey A. Denisov, ${ }^{[a, b]}$ Shinlin ${ }^{\text {(bu, }}{ }^{[a]}$ Jean-Luc Pozzo, ${ }^{[a]}$ Gediminas Jonusauskas, ${ }^{[b]}$ and \\ Nathan D. McClenaghan*[a]
}

Dedicated to the memory of the inspirational Dr. David R. Jones

Reversible electronic energy transfer (REET) may be instilled in $\mathrm{bi}$-/multichromophoric molecule-based systems, following photoexcitation, upon judicious structural integration of matched chromophores. This leads to a new set of photophysical properties for the ensemble, which can be fully characterized by steady-state and time-resolved spectroscopic methods. Herein, we take a comprehensive look at progress in the development

\section{Introduction}

Following photoexcitation of a chromophore, a range of processes can occur on varying timescales, the ultimate outcome is determined by management of the excess energy according to kinetic and energetic considerations. In a bi-/multichromophoric molecular system, energetically favourable electronic energy transfer can occur between chromophores when spectral overlap conditions are satisfied and interchromophore distance is sufficiently short. ${ }^{[1]}$ Typically this is a unidirectional process, with energy being transferred from a higher energy to a lower-energy chromophore. This unidirectional electronic energy transfer, typically using Förster energy transfer, has found many applications in terms of imaging, sensing and light-harvesting with multichoromophoric arrays. ${ }^{[1]}$ However, in specific cases, where low-lying, sufficiently long-lived excited states on adjacent chromophores are quasi-isoenergetic $\left(\Delta E \leq 1000 \mathrm{~cm}^{-1}\right)$, reversible energy transfer can be instilled. ${ }^{[2]}$

Once present, reversible electronic energy transfer (REET) can have profound effects on the observed properties of the molecule/ supramolecular assembly/ material. Indeed, as outlined below, this can prolong luminescence lifetime, change the nature of the excited state and be coupled to other photophysical processes, including photoinduced electron transfer.

[a] Dr. S. A. Denisov, S. Yu, Prof. J. L. Pozzo, Dr. N. D. McClenaghan Institut des Sciences Moléculaires

Université Bordeaux/ CNRS

351 crs de la liberation, 33405 Talence cedex (France)

E mail: nathan.mcclenaghan@u bordeaux.fr

[b] Dr. S. A. Denisov, Dr. G. Jonusauskas

Laboratoire Ondes et Matière O'Aquitaine

Université Bordeaux/ CNRS

351 crs de la liberation, 33405 Talence cedex (France) of this type of supermolecule in the last five years, which has seen systems evolve from covalently tethered dyads to synthetic molecular machines, exemplified by two different pseudorotaxanes. Indeed, REET holds promise in the control of movement in molecular machines, their assembly/disassembly, as well as in charge separation.

As such, applications as photosensitizers and in multicomponent light-harvesting and sensor systems have been envisaged. Most recently, REET has been implemented in molecular machines as a facilitator of function and to monitor the state of the system.

Due to the exacting set of requisite criteria, REET has only been observed between triplet states in a rather small chimiotheque of molecules, typically in transition metal-organic chromophore conjugates. ${ }^{[2,3]}$ This type of molecular platform is well-suited to inaugurate the REET process as energy transfer can occur efficiently from the inherently long-lived lowestlying triplet states of metal-to-ligand charge transfer states (MLCT), as well as organic triplets. The following section highlights the key considerations to satisfy in order to instill a REET process in a preordained fashion in a designer bichromophoric system.

While systems exhibiting this bidirectional electronic energy transfer behaviour have been previously comprehensively reviewed, the scope of this article considers very recent developments in the area (i.e. since ref. [3c]), with particular emphasis on systems recently developed in Bordeaux. After having resumed the pertinent parameters, recent covalent dyads implicating new components and functions leading to dynamic molecular machines are discussed.

\section{Prerequisite Parameters to Establish REET}

To establish reversible electronic energy transfer between matched chromophores, as schematized in Figure 1, specific conditions have to be fulfilled.

In terms of energy, the lowest-lying excited-state energies of the pertinent chromophores have to be very similar, such that available thermal energy is sufficient to overcome the energy gap, or the energy difference between pertinent lowest-lying 
excited states of each chromophore. While the available energy is temperature dependent, at room temperature, $k T$ is a few $\mathrm{kcal} \mathrm{mol}^{-1}$. For example, in the most studied bichromophoric dyads exhibiting REET, the matched chromophores are derivatives of pyrene and $\mathrm{Ru}(\mathrm{bpy})_{3}{ }^{2+}$, where bpy $=2,2^{\prime}$-bipyridine, and $\Delta E$ is circa $150 \mathrm{~cm}^{-1}$ and energy differences $>1000 \mathrm{~cm}^{-1}$ would effectively impinge on the reversibility of the transfer. ${ }^{[2]}$ Equally, the distribution of energy between states in a population of excited molecules after thermal equilibration can be modeled based on a Boltzmann-type distribution taking $\Delta E$ and $T$ into account. ${ }^{[4]}$ Another consideration is therefore degeneracy, when multichromophore systems are considered. In a scenario where efficient reversible interchromophore energy transfer is occurring, these processes are fast with respect to deexcitation parameters (vide infra), meaning

Sergey A. Denisov obtained his Ph.D. in molecular spectroscopy (electron and energy transfer) in 2014 at the University of Bordeaux, France, under the supervision of Dr. Gediminas Jonusauskas. In 2014, he continued his work as a postdoc in the Institut des Sciences Moléculaires with Nathan D. McClenaghan, working on fast photoinduced electron and energy transfer in molecular and supramolecular systems.

Shilin Yu obtained his bachelor degree in 2011 at the University of Jinan,

China, and studied supramolecular chemistry under the supervision of Prof. Da-Hui Qu in East China University of Science and Technology (2011 2014). He is currently working towards his Ph.D., which deals with photoresponsive supramolecular systems at the University of Bordeaux, France, under the supervision of Nathan McClenaghan and Jean-Luc Pozzo.

Jean-Luc Pozzo obtained his Ph.D. (1993) from Université de la Méditerranée (Marseilles) focusing on T-type photochromes. Essilor International PPG Industries offered him a grant for an industrial post-doctoral stay on tunable ophthalmic lenses. Since 2002, he has been full Professor at the University of Bordeaux, developing photoswitchable NLOphores and gelators as well as multi-addressable and multistate compounds. He was appointed Dean of the Sciences and Technologies Department in 2014.
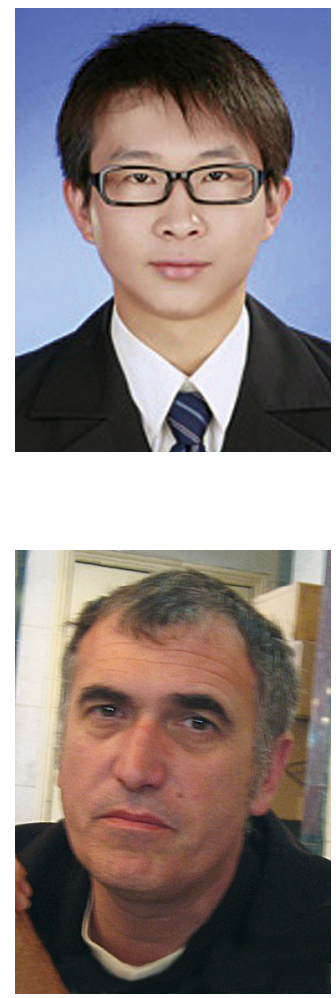
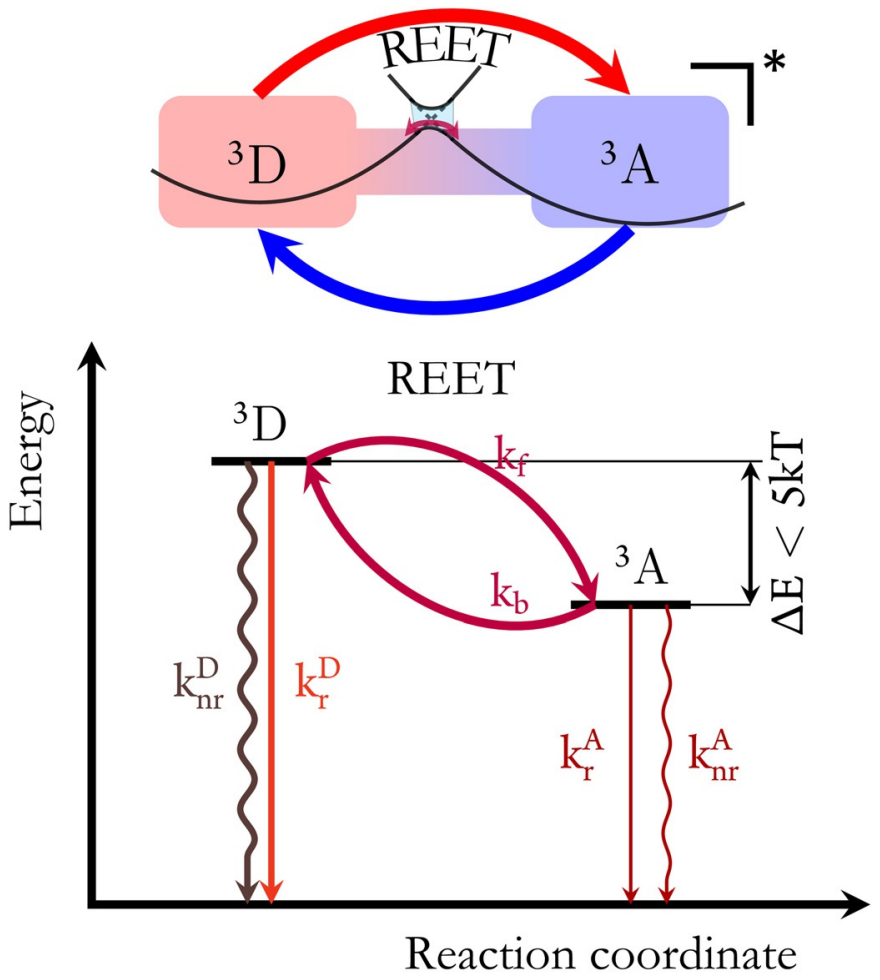

Figure 1. Schematic representation of reversible electronic energy transfer between triplet states of matched chromophores ( $D$ and A) and key kinetic and energetic prerequisites.

Gediminas Jonusauskas obtained his Ph.D. from Vilnius University in 1992, introducing for the first time the Optical Parametric Chirped Pulse Amplification (OPCPA) concept. Since moving to Bordeaux University and joining the CNRS in 1994, his activities deal with time-resolved emission and absorption spectroscopies applied to study the ultrafast processes in molecular systems: charge/electron and energy transfer, photoinduced molecular reactions.

Nathan D. McClenaghan is a CNRS research director at the University of Bordeaux, France. Since integrating the CNRS in 2003, his research work focuses on the conception and study of organic and inorganic supramolecular systems and fast photoinduced processes therein. He is laureate of the CNRS bronze medal for physical chemistry and recipient of an ERC young investigator grant.
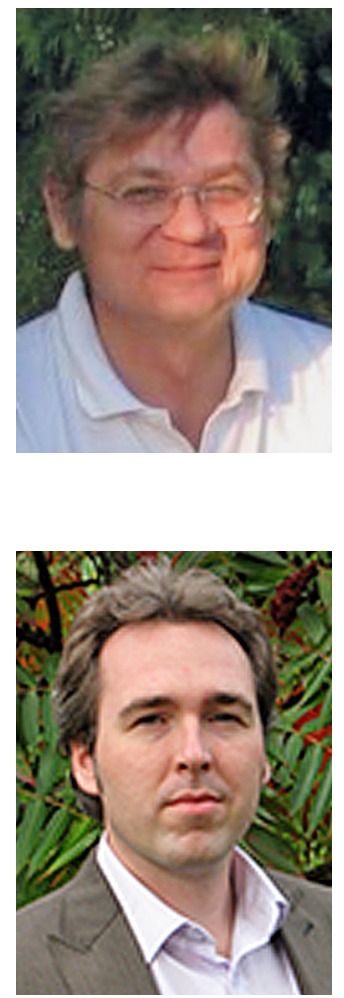
that following excitation a dynamic equilibrium is established with respect to instantaneous energy localization. As we are dealing with an equilibrium, this can be biased by the chemical entities involved, namely the presence of additional similar organic chromophores, for example, which will statistically increase the likelihood for energy to be located on the organic part with respect to the inorganic moiety. As energy is provisionally stored on the organic units before being transferred to, and emitted from, the inorganic unit, they are often referred to as energy reservoirs. The ratio of populated pyrenelike triplets to $\mathrm{Ru}(\mathrm{bpy})_{3}{ }^{2+}$-like triplets in the ensemble of molecules defines the excited-state equilibrium and is denoted $K_{\text {eq }}$. Indeed, studies of $\mathrm{Ru}(\mathrm{bpy})_{3}{ }^{2+}$-like chromophores bearing various numbers of appended pyrene chromophores were undertaken. ${ }^{[5]}$ Results show a linear increase in $K_{\text {eq }}$ with the number of appended chromophores and consequently the observed luminescence lifetime, $\tau$. For example, on passing from 0 appended pyrenes to 6 the lifetime increased from $0.7 \mu$ s to $18.1 \mu \mathrm{s}$ in degassed $\mathrm{MeCN}$, where each chromophore was seen to add on average $2.7 \mu \mathrm{s}$. $^{[5]}$ The origin of the prolonged luminescence lifetime with respect to the parent chromophore can be rationalized according to Equation (1), where $\tau_{\text {obs }}$ is the measured luminescence lifetime, $\tau_{0}$ is the luminescence lifetime of the emissive parent chromophore, $\alpha$ is the proportion of excited $\mathrm{Ru}(\mathrm{bpy})_{3}{ }^{2+}$-like triplets, and $1-\alpha$ is the proportion of pyrene-like triplets.

$\tau_{\mathrm{obs}}=\left(\alpha \tau_{0}^{-1}+\left(\begin{array}{ll}1 & \alpha\end{array}\right) \tau_{p y r}^{-1}\right)^{-1}$

Clearly, the resulting lifetime is a weighted average of the contribution of each chromophore, namely, the inherent lifetime and population. As organic triplet states are more persistent than ${ }^{3} \mathrm{MLCT}$ states, which in turn de-excite relatively slowly (rates of circa $10^{3} \mathrm{~s}^{-1}$ versus $10^{5} \mathrm{~s}^{-1}$ ), this gives a good opportunity to set up reversible interchromophore electronic energy transfer, which relies on faster energy transfer, on paying particular attention to the relative energies. Equally, this kinetic ordering ensures that energy will be primarily emitted from the inorganic moiety. When energy transfer processes are efficient, observed quantum yields have proved to be essentially unaffected with respect to the parent dye.

Concerning the approach to equilibrium, this corresponds to a sum of the rate constants for forward $\left(k_{\mathrm{f}}\right)$ and backward $\left(k_{\mathrm{b}}\right)$ energy transfer, and a short-lived emission component (typically ps to ns) in addition to the long-lived luminescence emanating for the equilibrated excited states corresponds to this process.

Concerning kinetic considerations, following photoexcitation of the metal centre, intersystem crossing from the initially populated ${ }^{1} \mathrm{MLCT}$ excited state to the lower-lying ${ }^{3} \mathrm{MLCT}$ state in transition metal complexes typically occurs on the sub-picosecond timescale, the most important states to consider in an interchromophore energy transfer process are the triplet states. As these states are typically inherently long-lived, this gives ample time for the interchromophore energy transfer to occur, ensuring that both the forward and slower backward energy transfer processes (typically on a nanosecond timescale) can successfully compete with deexcitation to the ground state (typically on a microsecond timescale). This is of course true for covalent dyads where the interchromophore distance is subnanometric and is not necessarily valid for bimolecular electronic energy transfer, which is typically diffusion-limited. In covalent dyads with matched chromophores as cited above, energy can migrate freely between the two chromophores and set up a dynamic excited-state equilibrium before being reemitted. Triplet-triplet energy transfer via a Dexter mechanism is considered to be rather short range, see Equation (2), where $J$ is the integral overlap between the normalized donor emission and acceptor absorption spectra, $L$ is the effective average Bohr radius of the excited and unexcited states of the donor and acceptor $(0.7-6 \AA$, with an average value of $1.5 \AA),{ }^{[6]}$ and $K$ is the experimental factor.

$k_{\text {dexter }}=K J \exp \left(\frac{2 R_{D A}}{L}\right)$

\section{REET in Covalently Tethered Dyads}

Figures 2 and 3 show a range of recently reported conjugates exhibiting REET, which is discussed herein. Please note that spectator counteranions are omitted throughout. Among the emitting centres, the most commonly studied involve ruthenium(II) polypyridine complexes. On changing the metal coordination environment, significant changes in properties may be anticipated. ${ }^{[7]}$ Polypyridine ligands typically bind in a bidentate or tridentate fashion, with tridentate ligands offering complexes with 1D linear geometries (molecular rods and wires). However, their luminescence properties are typically inhibited by thermally accessible metal-centred states. $\left[\mathrm{Ru}(\mathrm{tpy})_{2}\right]^{2+}$ (tpy $=2,2^{\prime} ; 6^{\prime}, 2^{\prime \prime}$-terpyridine) has a correspondingly low emission quantum yield $\left(<10^{-5}\right)$ and short lifetime $(0.25 \mathrm{~ns}){ }^{[7]}$ The photophysical properties may be improved by design, on defavouring thermally-activated loss by increasing the energy gap between states on lowering emissive ${ }^{3} \mathrm{MLCT}$ levels, as a result of incorporating highly electron poor tpy-like ligands. ${ }^{[8]}$ Furthermore, integration of an organic auxiliary led to luminescence lifetimes as long as $1.8 \mu$ s but with a similarly low quantum yield. ${ }^{[9]}$ More recently, ruthenium complexes exhibiting microsecond luminescence lifetimes were reported on replacing the two external pyridine moieties of tpy with quinolines in constituent ligands, which offers an optimized octahedral coordination environment. ${ }^{[10]}$

Further optimization of such an emissive ruthenium bichromophore was envisaged on judicious integration of an auxiliary chromophore with matched properties, with the goal of giving access to a much longer-lived luminescent complex, while retaining a similar emission quantum yield. Anthracene was anticipated to be an appropriate candidate with the adjacent MLCT state (triplet energy at $1.8 \mathrm{eV} ; \tau_{\text {phos }}=3300 \mu \mathrm{s}$ in polar solvent), whose incorporation gave the prototype $\left[\mathrm{Ru}(1)_{2}\right]^{2+} .^{[11]}$ While the parent complex gave an emission lifetime of $2.7 \mu \mathrm{s}^{[12]}$ bichromophore $\left[\mathrm{Ru}(1)_{2}\right]^{2+}$, by taking advant- 

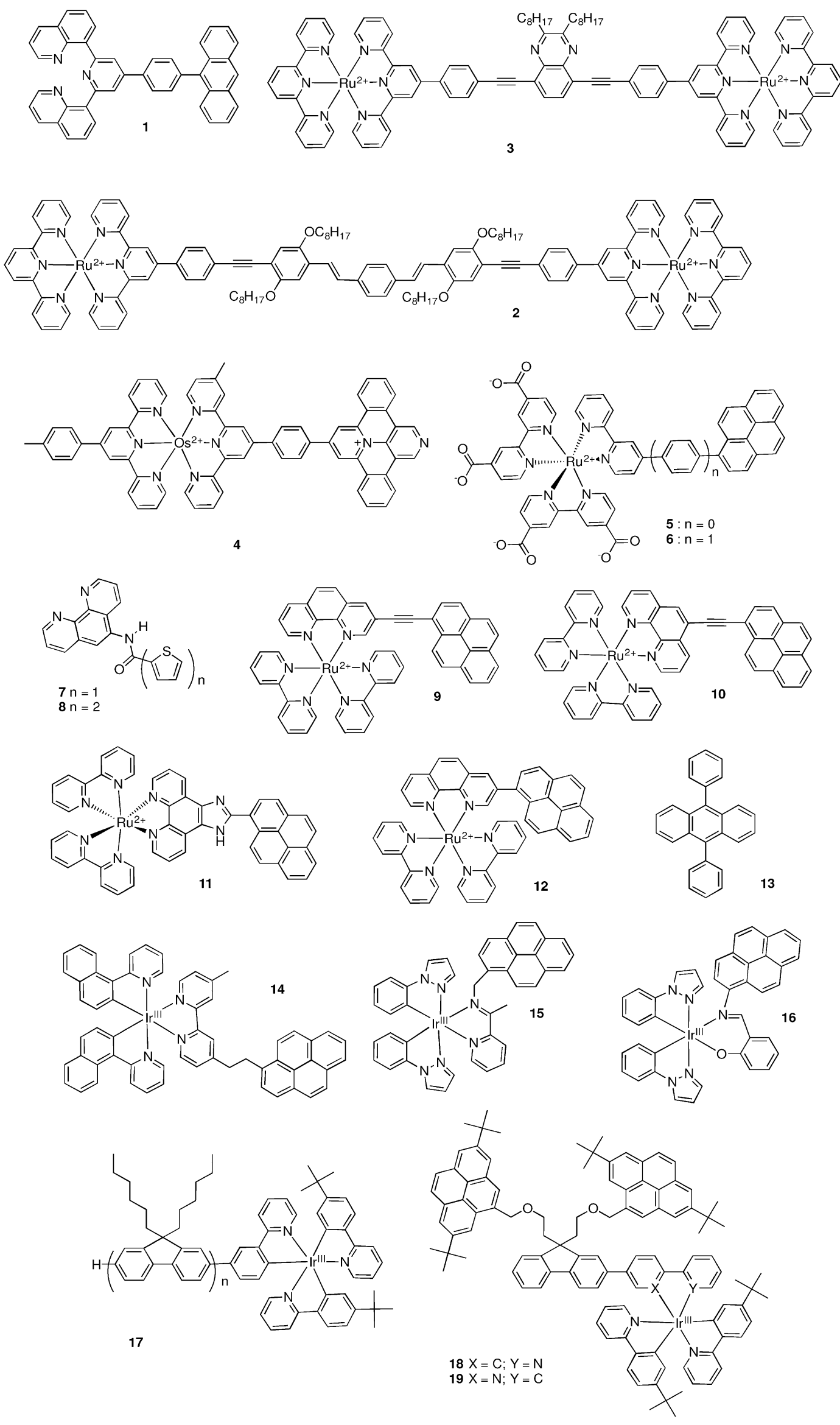

Figure 2. Structural formulas of recently reported molecular systems exhibiting REET (or related processes). 

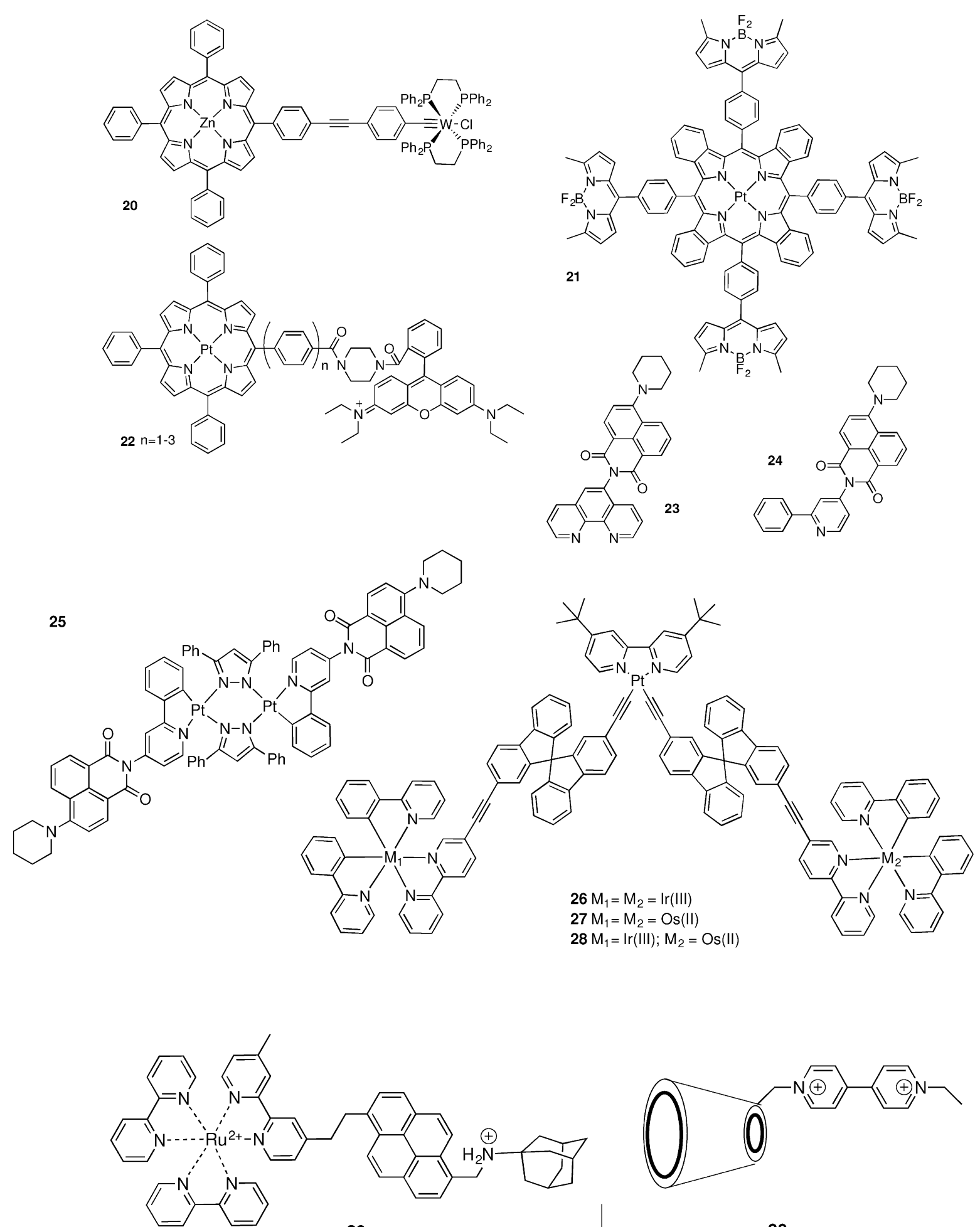

29

30

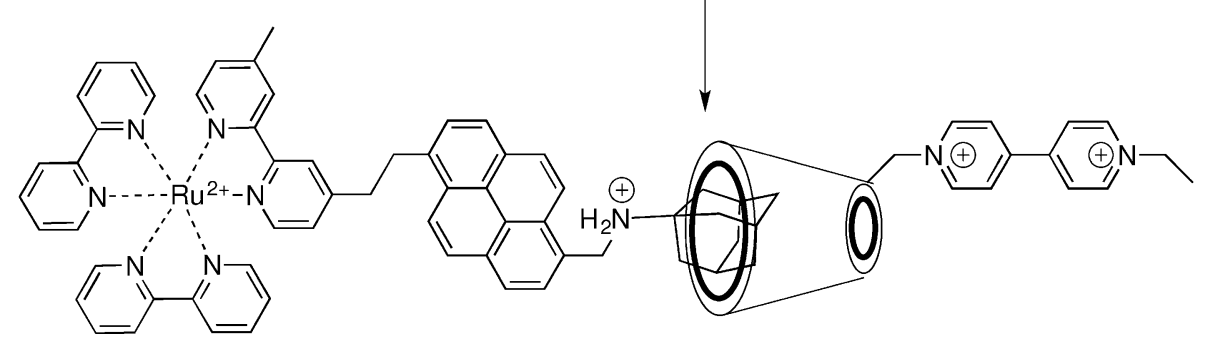

Figure 3. Structural formulas of recently reported molecular systems exhibiting REET (or related processes). 
age of REET and an optimized coordination environment, gave a long room temperature luminescence lifetime (42 $\mu \mathrm{s})$ and a $\Phi_{\text {em deoxy }} / \Phi_{\text {em oxy }}$ ratio value of 33 . Kinetic analysis via transient absorption measurements allowed determination of the chromophore energy gap at $430 \mathrm{~cm}^{-1}$, while phosphorescence at $77 \mathrm{~K}$ showed pyrene emission, evidencing this as the lowerlying excited state. Excited-state equilibrium was obtained in $75 \mathrm{ps}$ and the equilibrated population was to be largely (94\%) in favour of the organic chromophore, and equilibrium constant $K_{\text {eq }}$ at $15.2 \pm 2$. Thus, $k_{\mathrm{f}}$ and $k_{\mathrm{b}}$ were determined at $1.25 \times$ $10^{10}$ and $8.30 \times 10^{8} \mathrm{~s}^{-1}$, respectively.

Some dinuclear ruthenium terpyridine complexes (see examples 2 and 3) bearing electron-poor bridging ligands were reported to exhibit REET. ${ }^{[13]}$ These compounds, which present building blocks of photoactive coordination polymers, show red room-temperature emission around $640 \mathrm{~nm}$ and prolonged lifetimes between 140 and 230 ns. Variable temperature experiments show an overall increase of emission lifetime at lower temperature, which is bridging-ligand dependent. The behavior was rationalized based on the electronic structure of the ligand, and the interplay of several excited states (MC, MLCT, $\left.\pi-\pi^{*}\right)$ and an excited-state equilibrium between a highly delocalized ${ }^{3}$ MLCT and a ligand-centered ${ }^{3} \pi-\pi^{*}$ excited-state was observed in line with theoretical predictions.

Molecular dyads of ruthenium(II) bis(terpyridine) chromophores and various expanded pyridinium electron acceptors and the osmium-containing homologues have been reported. ${ }^{[14]}$ Molecular dyads such as $\mathbf{4}$ were designed such that their MLCT and charge-separated (CS) states are close in energy, allowing excited-state equilibration between these levels to take place. While not directly concerning REET, the kinetic scheme is similar to that described above. CS states are formed from MLCT states with time constants of a few dozens of picoseconds. These experimental time constants were shown not to be due to photoinduced charge separation but are related to the excited-state equilibration times. Thus one can envision conceiving new photochemical molecular devices that rely on charge-separation processes with such very small driving forces to minimize energy loss during some energy transduction steps.

The control of reversible excited-state energy transfer processes as a response to a variation of $\mathrm{pH}$ in aqueous solution in the $\mathrm{pH} 4-7$ range was demonstrated in other rutheniumpyrene complexes (5 and 6). ${ }^{[15]}$ Effectively, protonation of carboxylates on two bipyridine ligands lowers the MLCT level relative to the unchanging pyrene triplet level and modulates the effective $\Delta E$ and hence excitation energy distribution between chromophores, in analogy to second coordination sphere effects of solvent acidity (Guttman no.) on other rutheniumpyrene dyads. ${ }^{[16]}$ Consequently, the observed luminescence lifetime varies in the range of $2 \mu \mathrm{s}$ at $\mathrm{pH} 0$ to $>10 \mu \mathrm{s}$ at higher $\mathrm{pH}$ as the equilibrium favors population of the pyrene triplet. Mirroring the $\mathrm{pH}$-sensitive lifetime, oxygen quenching of the excited molecule shows a $\mathrm{pH}$ dependence of the excited state lifetime.

Appending bithienyl groups onto ruthenium complexes gave long-lived charge-separated excited states $(\tau \approx 3-7 \mu \mathrm{s})$ and a large amount of stored energy $\left(\Delta G^{0} \approx 2.0 \mathrm{eV}\right)$ in complexes $\left[(\text { phen })_{2} R u 7\right]^{2+},\left[(\text { phen })_{2} \operatorname{Ru} \mathbf{8}\right]^{2+},\left[\operatorname{Ru}(\mathbf{7})_{3}\right]^{2+},\left[\operatorname{Ru}(\mathbf{8})_{3}\right]^{2+}$; phen $=1,10$-phenanthroline. The long-lived ligand-localized triplet serves as an energy reservoir, which can populate an interligand charge-transfer state via an intermediate MLCT state. $^{[17]}$

Mononuclear $\mathrm{Ru}^{\prime \prime}$ complexes possessing a phenanthroline ligand appended with matched ethynylpyrenyl groups in the 3 or 5 position $\left(\left[(\text { bpy })_{2} R u(9)\right]^{2+}\right.$ and $\left[(\text { bpy })_{2} R u(10)\right]^{2+}$ ) were developed with the goal of utilizing their potential in photobiological applications including photodynamic therapy (PDT). ${ }^{[18]}$ PDT relies on employing a photosensitizer possessing a long-lived triplet excited-state which can transfer energy to ground state ${ }^{3} \mathrm{O}_{2}$ to generate singlet oxygen, which serves as an active therapeutic agent in attacking cancer cells. A range of dyads in this series possess extremely long lowest-lying triplet intraligand ( $\left.{ }^{3} \mathrm{IL}\right)$-based excited states with lifetimes that can be tuned from 22 to $270 \mu \mathrm{s}$ in fluid solution and from 44 to $3440 \mu$ s in glass at $77 \mathrm{~K}^{[19]}$ Intercalation was identified as a major binding mode for $\left[(\text { bpy })_{2} \mathrm{Ru}(9)\right]^{2+}$ and $\left[(\mathrm{bpy})_{2} \mathrm{Ru} 10\right]^{2+}$, with both complexes photocleaving DNA upon photoirradiation $\left(\lambda_{\text {irr }}=400 \mathrm{~nm}\right)$, comparing favourably with currently-used PDT photosensitizer lutetium(III) texaphyrin (LuTx). Both DNA binding and photocleavage were shown to depend on the position of the ethynylpyrenyl substituent on the 1,10-phenanthroline ring, with $\left[(\mathrm{bpy})_{2} \mathrm{Ru}(10)\right]^{2+}$ proving most effective. Both dyads photocleave DNA under hypoxic conditions, and this photoactivity translates well to cytotoxicity and photocytotoxicity models using human leukemia cells. The 5- and 3-substituted dyads show photocytotoxicity at 5-10 and 10-20 $\mu \mathrm{m}$, respectively, with minimal dark toxicity at these concentrations. This suggests that agents with strong intercalating units can have a role to play as photochemotherapeutic agents. It is noteworthy that the dyad photocytotoxicity results in apoptosis, an important consideration in the development of new therapeutic molecules.

Replacing, for example, the ethenyl spacer gave imidazo[4,5f] $[1,10]$ phenanthroline framework, which offers a convenient tether for Ru-pyrene dyads. The resulting dyads (11) exhibited nanomolar light cytotoxicities against cancer cells with photocytotoxicity indices $>400$ for some of the coligands employed. This potency was applicable for bacteria, where even low concentrations (10 nM) destroyed $75 \%$ of a bacterial population. Notably, these dyads remained extremely active against a biofilm with light photocytotoxicities against these more resistant bacterial populations in the $10-100 \mathrm{~nm}$ regime. These results highlight the versatility of these highly potent photosensitizers in destroying both cancer and bacterial cells and widen the scope of compounds with low-lying ${ }^{3} \mathrm{IL}$ states for photobiological applications. ${ }^{[20]}$

The role in REET in a ruthenium-pyrene bichromophore ( 9 and 12) in improving the photosensitizer properties was demonstrated in another scenario, namely, as efficient triplet sensitizers for low-power upconversion. ${ }^{[21]}$ Here, upconversion (UC) corresponds to the observation of higher emission (or population of excited states) after photoexcitation with lower energy light, which could in principle impact applications such as 
solar cells, photocatalysis, photonics, and molecular probes. Triplet-triplet annihilation (TTA) based upconversion, which can draw on a wealth of chromophores and materials, was previously using a transition metal complex, which can populate, for example, the triplet state of an anthracene $\left({ }^{3} \mathrm{Anth}{ }^{*}\right.$, triplet energy $=1.8 \mathrm{eV}$ ) derivative in a bimolecular regime; when two ${ }^{3}$ Anth* encounter each other a highly energetic, blue-emitting ${ }^{1}$ Anth* is produced. ${ }^{[22]}$ Long-lived ${ }^{3} \mathrm{IL}$ excited state $(\tau=58.4 \mu \mathrm{s})$ and the equilibrated ${ }^{3} \mathrm{MLCT} /{ }^{3} \mathrm{IL}$ excited state $(\tau=9.22 \mu \mathrm{s})$ of pyrene-containing Ru" complexes 9 and 11 efficiently sensitized TTA-based upconversion, with 9,10-diphenylanthracene (DPA, 13) as the acceptor/annihilator. Visible laser excitation results in upconverted fluorescence at $400 \mathrm{~nm}$, notably with an anti-Stokes shift of up to $0.77 \mathrm{eV}$. Equally, power density of the excitation employed was $0.07 \mathrm{~W} \mathrm{~cm}^{-2}$, and is therefore lower than terrestrial solar radiation. The measured quenching constant of the ${ }^{3} \mathrm{IL}$ state with DPA is much higher (223 times) than that of the ${ }^{3} \mathrm{MLCT}$ state. The upconversion quantum yield $\left(\Phi_{U C}=9.6 \times 10^{-2}\right)$ of the long-lived ${ }^{3} \mathrm{IL}$ excited state is circa ten times higher than parent $\left[\mathrm{Ru}(\mathrm{dmb})_{3}\right]^{2+}, \mathrm{dmb}=4,4^{\prime}$-dimethyl2,2'-bipyridine, $\left(\Phi_{\mathrm{UC}}=1.0 \times 10^{-2}\right)$, for which the shorter lived ${ }^{3} \mathrm{MLCT}$ state $(\tau=0.84 \mu \mathrm{s})$ dominates.

Modification of the photophysical properties of cyclometalated iridium complexes is of particular interest because of their central role in a range of applications that require highly efficient emission such as electroluminescence, sensing and bioimaging. ${ }^{[23]}$ A cyclometalated iridium complex (14) was recently reported where the complex comprises naphthylpyridine as the principal ligand and the pyrene unit is attached to a 2,2'-bipyridine ancillary ligand by a short saturated alkyl bridge. Time-resolved spectroscopies showed reversible electronic energy transfer (REET) between the close low-lying lying excited states $\left(\Delta E=680 \mathrm{~cm}^{-1}\right)$. An excited-state equilibration was attained ( $5 \mathrm{~ns}$ ) and subsequently extremely long luminescence lifetimes of up to $225 \mu$ s result, compared to $8.3 \mu$ s for the model complex, without discernably diminishing the emission quantum yield. $K_{\text {eq }}$ was thus estimated to be $27.8 \pm 2$, such that the equilibrated population is predominantly (96.5\%) in favor of the organic chromophore. In solution and host matrices (a polymeric PS 398 membrane and a nanostructured metal oxide matrix (AP200/19)), remarkably high oxygen sensitivity is observed. ${ }^{[24]}$ Some bis-cyclometalated $\mid \mathrm{Ir}^{\mathrm{II}}$ complexes (15 and 16) with the general formula $\operatorname{Ir}(1-$ phenylpyrazole $)_{2}(X \wedge N P y r e n e)$, where $X \wedge N P y r e n e$ represent synthetically easily accessible bidentate chelate with $\mathrm{X}=\mathrm{N}$ or $\mathrm{O}$, were also reported. ${ }^{[25]}$

Even subtle modifications on the pyrene-containing ligand dramatically affected the observed emission lifetimes in the range 0.33 to $104 \mu \mathrm{s}$. Comparison with non-pyrene containing model complexes showed extended emission lifetimes as a result of REET in solution or the observation of dual emission containing a long-lived pyrene ligand-centred triplet $\left({ }^{3} \mathrm{LC}\right)$ component in a PMMA film. This underlines the exacting criteria for efficient REET.

On studying a wide range of cyclometallated Ir complexes bearing different ligands and an oligofluorene unit, the authors identified 17 as being the sole candidate exhibiting REET. ${ }^{[26]}$
Here, a luminescence lifetime of $114 \mu$ s was observed, where the reservoir component involves a trifluorene appendage rather than pyrene units. More recently the same laboratory reported cyclometalated iridium complexes that were grafted with a single fluorene unit, which is appended by two pyrene groups (18 and 19) and, due to REET, were shown to possess extremely long lifetimes in the 1-2 ms range. ${ }^{[27]}$ The authors ascribe a significant decrease in emission quantum yields with respect to model complexes as resulting from non-negligible losses from the extremely long-lived species as other processes start to become important on these timescales. Subsequently they proved efficient photosensitizers for efficient triplet-triplet annihilation upconversion with a ditertbutyl pyrene annihilator at very low concentration, with TTA upconversion quantum efficiencies of $4.1 \times 10^{-2}$ and $3.2 \times 10^{-2}$.

Some recent examples of REET involving porphyrins have been described. A zinc tetraphenylporphyrin, Zn(TPP), bearing an adjacent tungsten alkylidyne moiety (20) was shown to undergo REET resulting in $a>1000$-fold luminescence lifetime augmentation in specific cases. ${ }^{[28]}$ The enhanced lifetime of the dyad (20 times that of the parent) can be accounted for by a thermal equilibrium between the emissive ${ }^{3}\left(d_{x y} \leftarrow \pi^{*}\right)$ state of the tungsten fragment and the longer-lived ( $\tau=1.25 \mu \mathrm{s})$, nonemissive $T_{1}$ state of the porphyrin moiety which is in close proximity $\left(\Delta E=\right.$ ca. $\left.600 \mathrm{~cm}^{-1}\right)$. Interestingly, the triplet-triplet equilibrium can be tuned by the addition of ligating to the $\mathrm{Zn}$ centre (pyridine, 4-picoline, 4-(dimethylamino)pyridine and imidizole), which coordinate to $\mathrm{Zn}$ (TPP) with binding constants of $10^{3}-10^{4}$. Lifetimes in the range of $77 \mu$ s (20.imidazole) to $139 \mu$ s (20.DMAP) were measured, relative to the parent 20 $(\tau=2 \mu \mathrm{s})$.

A multichromophoric array based on four boron dipyrrins (BODIPY) bound to a platinum benzoporphyrin scaffold that exhibits intense panchromatic absorption and efficiently generates triplets was reported (21). ${ }^{[29]}$ Fast bidirectional singlet and triplet interchromophore energy transfer processes were observed $\left(k_{\mathrm{SS}}\left({ }^{1} \mathrm{BDP} \rightarrow{ }^{1} \mathrm{Por}\right)=7.8 \times 10^{11} \mathrm{~s}^{-1}, \quad k_{\mathrm{TT}}\left({ }^{3} \mathrm{Por} \rightarrow{ }^{3} \mathrm{BDP}\right)=1.0 \times\right.$ $\left.10^{10} \mathrm{~s}^{-1}, k_{T}\left({ }^{3} \mathrm{BDP} \rightarrow{ }^{3} \mathrm{Por}\right)=1.6 \times 10^{10} \mathrm{~s}^{-1}\right)$, which led to a longlived equilibrated $\left[{ }^{3} \mathrm{BDP}\right][\mathrm{Por}]=[\mathrm{BDP}]\left[{ }^{3} \mathrm{Por}\right]$ state. This equilibrated state comprises porphyrin and BODIPY triplets and phosphoresces in the near-infrared $\left(\lambda_{\mathrm{em}}=772 \mathrm{~nm}, \Phi=0.26\right)$.

In another Pt-porphyrin dyad (22), photoinduced electron transfer across a linear oligophenylene bridge results in generation of phosphorescent triplet states. The sequence being porphyrin-to-rhodamine B derivative electron transfer to generate singlet radicals, intersystem crossing and triplet radical charge recombination populating a rhodamine triplet which is quasi-isoenergetic with that of the Pt-porphyrin. REET was observed between the partners, and an attenuation factor of energy transfer rate versus interchromophore distance of $0.3 \AA^{-1}$ was estimated. ${ }^{[30]}$

Rylene chromophores have equally proven effective partners for transition metal complexes in obtaining functional dyads; ${ }^{[31]}\left[\mathrm{Ru}(\mathrm{bpy})_{2}(23)\right]^{2+}$ and $\left[\mathrm{Ru}(23)_{3}\right]^{2+}$ have excited-state lifetimes ranging from 16 to $115 \mu \mathrm{s}$, depending on both the number of PNI subunits and the solvent. ${ }^{[32]}$ Nanosecond stepscan Fourier transform infrared spectroscopy studies were un- 
dertaken on these complexes, and showed that the imide $\mathrm{C}=\mathrm{O}$ bands were red shifted by $60-100 \mathrm{~cm}^{-1}$, as a result of the formation of the ligand-localized triplet state on the piperidinyl naphthalidimide (PNI) subunit(s) in agreement with DFT calculations. ${ }^{[33]}$ The homologous $\operatorname{Re}(23)(\mathrm{CO})_{3} \mathrm{Cl}$ bichromophoric complex gave outstanding excited state MLCT lifetimes (650 $\mu \mathrm{s}$ ). This represented a net 3000-fold increase in lifetime with respect to the $\operatorname{Re}($ phen $)(\mathrm{CO})_{3} \mathrm{Cl}$ charge-transfer model compound. ${ }^{[34]}$ Following initial excitation of the PNI chromophore, energy is transferred, ultimately leading to the ${ }^{3} \mathrm{MLCT}$ state with a time constant of 45 ps. Triplet energy was transferred from the ${ }^{3} \mathrm{MLCT}$ state, populating the PNI-centered ${ }^{3} \mathrm{LC}$ state in less than $15 \mathrm{~ns}$, and the slow-decaying equilibrium mixture was reached.

The PNI was judiciously modified with respect to the chelating group giving 24, allowing, for example, the formation of dinuclear cyclometalled platinum(II) complexes with pyrazolate bridging ligands. ${ }^{[35]}$ In this configuration, where filled $\mathrm{d}_{\mathrm{z}}{ }^{2}$ orbitals on each Pt centre overlap, a Pt-Pt $\sigma$ interaction and lowenergy metal-metal-to-ligand charge transfer (MMLCT) transitions resulted, which were matched with the PNI energy reservoirs. Temperature-dependent transient absorption spectroscopy permitted energy gap determination $\left(1740 \mathrm{~cm}^{-1}\right)$ between the MMLCT and PNI triplet states along with the time constants associated with the interconversion between excited states, which decayed to the ground state with a time constant of $65 \mu \mathrm{s}$. Zhao and Zhang reported another example where a triplet equilibrium was proposed between a Pt and a rylene dye. ${ }^{[36]}$

A range of spirobifluorene bridged heteroleptic mono- and trinuclear complexes comprising Pt", Os" and Ir"l metals were described (26-28). ${ }^{[37]}$ Here, the luminescence of the tetrad consisting of spirobifluorene-bridged $\mathrm{Pt}$, Ir and Os complexes were studied by comparison with the reference complexes bearing two identical luminophores (Ir or Os) at the periphery. The ${ }^{3} \mathrm{M}_{\mathrm{Pt}} \mathrm{LCT}$ and ${ }^{3} \mathrm{LC}$ states of the Pt and spiro ligand undergo fast energy transfer into the ${ }^{3} \mathrm{M}_{\mathrm{Ir}} \mathrm{LCT}$ or the ${ }^{3} \mathrm{M}_{\mathrm{Os}} \mathrm{LCT}$ state in the Pt$\mathrm{M}_{2}\left(\mathrm{M}=\mathrm{Ir}\right.$ or Os) arrays, while ${ }^{3} \mathrm{LC}$ and ${ }^{3} \mathrm{M}_{\mathrm{Pt}} \mathrm{LCT}$ states serve as energy reservoirs for the quasi-isoenergetic metal excited states, resulting in a extended excited state lifetime in the arrays. In the tetrad antenna system, the collected light energy is ultimately transferred to the Os unit.

\section{REET in Dynamic Molecular Machines}

Beyond covalent bichromophoric dyads, where REET can primarily affect the observed dye properties, REET has been recently shown to intervene in different ways in two distinct types of pseudorotaxane assembly.

Figure 4 shows a representation of the operation of a benchmark molecular piston, this pseudorotaxane being previously reported by Balzani and Stoddart. ${ }^{[38]}$ This dynamic assembly comprises a thread (blue) with a central electron-rich dialkoxynaphthalene unit, which spontaneously forms a charge-transfer complex in the guise of the threaded supermolecule in the presence of the electron-poor $\left(E_{\text {red }}=0.35 \mathrm{~V}\right.$ vs. SCE) tetracationic cyclophane (represented as a red doughnut), evidenced

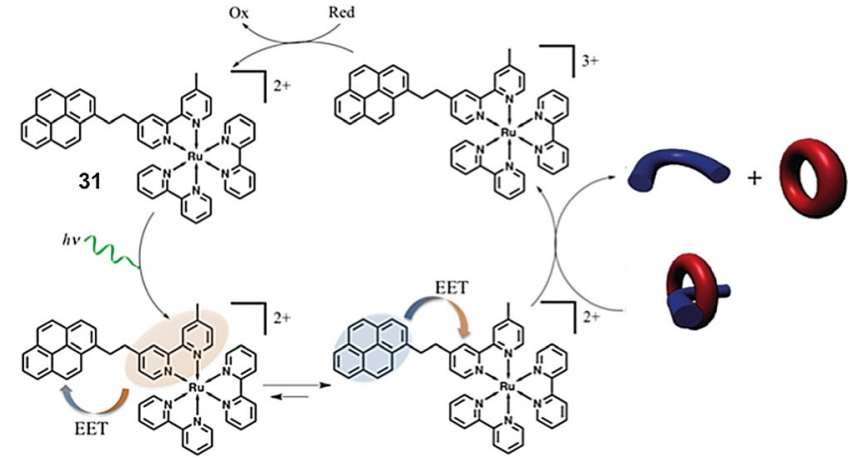

Figure 4. Reversible electronic energy transfer enhanced photocatalytic elec tron pumping driving a molecular piston (blue thread, red host). Photoirra diation of photosensitizer $\mathbf{3 1}$ induced reduction and disassembly of the pseudorotaxane in the presence of a sacrificial reductant. Addition of $\mathrm{O}_{2}$ reset the system, reassembling the molecular piston. ${ }^{[41]}$

by a characteristic broad featureless absorption band in the visible spectral region. For the piston to function, the alternating threading/ dethreading processes should occur in response to specific stimuli. This can be achieved by a monoelectronic reduction of the cyclophane, which destabilizes the charge transfer complex leading to dethreading of the complex. Oxidation of the reduced cyclophane allows for rethreading, completing the two-stroke cycle. The reduction step can be accomplished by a photoinduced electron transfer from a sufficiently long-lived excited photosensitizer such as $\mathrm{Ru}(\mathrm{bpy})_{3}{ }^{2+}$ in solution, in the presence of a large excess of a suitable sacrificial reductant (triethanolamine) to retard unwanted back electron transfer. Meanwhile the oxidation step can be achieved on addition of oxygen.

On replacing the parent $\mathrm{Ru}(\mathrm{bpy})_{3}{ }^{2+}$ with an analogue exhibiting REET, it was anticipated that more effective bimolecular sensitization could occur based on the prolonged excited-state lifetime as well as the nature of the donor. Indeed, when REET is operational, the energy is predominantly localized on the organic chromophore. Aromatic triplets are often considered better electron donors than MLCT states for spin-orbit considerations and an enhanced solvent cage escape of the germinate radical pair, thus limiting competitive back electron transfer ${ }^{[39]}$ Intervention of REET was previously demonstrated in enhancing electron pumping from a photosensitizer internalized in a zeolite framework to an externalized electron acceptor, facilitated by charge compensation resulting from cation movement. ${ }^{[40]}$

Figure 4 shows the general scheme for the operation of a molecular piston, where the concatenation of two photophysical processes, namely, reversible electronic energy transfer and photoinduced electron transfer, conspire to offer an enhanced dethreading efficiency of the molecular piston, which can be reversed on addition of $\mathrm{O}_{2} \cdot{ }^{[41]}$ Upon visible irradiation, the initially yellow solution became blue, which is diagnostic of the formation of the monoreduced viologen. Following absorption changes $(\lambda=725 \mathrm{~nm})$, the efficiency of reduction on photoirradiation can be assessed. The quantum efficiency of the dethreading process is $\Phi_{\text {diss }}=1.2 \times 10^{-3}$ for the 
parent $\mathrm{Ru}(\mathrm{bpy})_{3}{ }^{2+}$, which has a lifetime of $0.95 \mu \mathrm{s}$. By comparison, modified $\mathrm{Ru}(\mathrm{bpy})_{3}{ }^{2+}$-like photosensitizers integrating one or three pyrene chromophores with lifetimes of 3.3 and $7.4 \mu \mathrm{s}$ gave improved values of $\Phi_{\text {diss }}=2.2 \times 10^{-3}$ and $3.9 \times 10^{-3}$, respectively. Each photosensitizer molecule was demonstrated to act catalytically, provoking the threading of multiple pistons. Return to the initial condition was achieved on adding oxygen with no evidence of degradation allowing multicycle use.

Appending the photosensitizer $\mathbf{3 1}$ in the previous case with an adamantane recognition motif gave $\mathbf{2 9}$, which allowed formation of a supramolecular 1:1 host-guest assembly in aqueous solution in the presence of a $\beta$-cyclodextrin $(\beta-C D)$, see Figure 3 , where $\beta-C D$ is represented as a cone. A photo-/ electroactive triad was formed when the $\beta-C D$ bore a pendant methylviologen (MV), 30. Thus, the Ru" polypyridyl derivative acted as the light absorber, pyrene as the primary electron donor and methylviologen as the primary acceptor. ${ }^{[42]}$ Laser flash photolysis experiments confirmed the formation of $\mathrm{Py}^{\cdot+}$ and $\mathrm{MV}^{\cdot+}$, giving $\mathrm{Ru}^{\prime \prime}-\mathrm{Py}^{\cdot+}-\mathrm{MV}^{\cdot+}$. Electron transfer occurs from a triplet state and the radical ion pairs are formed in the triplet state. Back electron transfer in the triplet radical ion pair is slow, being formally forbidden. A subsequent electron transfer then takes place from $\mathrm{Ru}^{\prime \prime}$ to $\mathrm{Py}^{*}$ to give the charge-separated $\mathrm{Ru}^{\text {III-Py-MV }}{ }^{+}$assembly, as shown by the appearance of a ground-state bleaching in the transient absorption spectrum. As $\mathrm{Ru}^{\mathrm{III}}$ and $\mathrm{MV}^{+}$centres are distant, the charge-separated state proved long lived (100 $\mu \mathrm{s})$.

In the former example, REET was used to intervene in the functioning of a molecular machine. Equally, bichromophores exhibiting REET can be used to report on the state of a molecular machine, as outlined below.

A foldamer is an artificial discrete chain molecule/ oligomer, which folds into a conformationally ordered state in solution. Using noncovalent interactions between nonadjacent monomers, they mimic the propensity of proteins, nucleic acids, and polysaccharides to fold into specific conformations such as helices and $\beta$-sheets. ${ }^{[43]}$ Recently, foldaxanes have been described, which are helical aromatic oligoamide foldamers wound around a linear molecular axis in analogy to rotaxanes. $^{[44]}$

In a proof-of-principle example, the observation of real-time threading of a bichromophoric thread 32 inside the void of a double helix $(33)_{2}$ leading to a foldaxane was demonstrated on monitoring the luminescence lifetime, see Figure $5 .{ }^{[45]}$ Molecule 32 comprises terminal $\mathrm{Ru}(\mathrm{bpy})_{3}{ }^{2+}$ and pyrene chromophores, which are separated by a long (circa $2 \mathrm{~nm}$ ) flexible bridge. In free solution, the molecular thread can freely move around, allowing the distant chromophores to encounter one another during the lifetime of the excited-state. Thus REET can be installed and a long resulting luminescence lifetime may be anticipated. A biexponential luminescence lifetime was observed ( $\tau=28 \mathrm{~ns}$ and $2.5 \mu \mathrm{s}$ ) corresponding to the time of approach to equilibrium and the deexcitation of the excited molecular system. This relatively slow approach to equilibrium was ascribed to the long spacer. Indeed, the distribution of distances between the ruthenium core and pyrene is described by a Gaussian function centred at $1.0 \mathrm{~nm}(\mathrm{FWHM}=0.5 \mathrm{~nm}) .{ }^{[46]}$

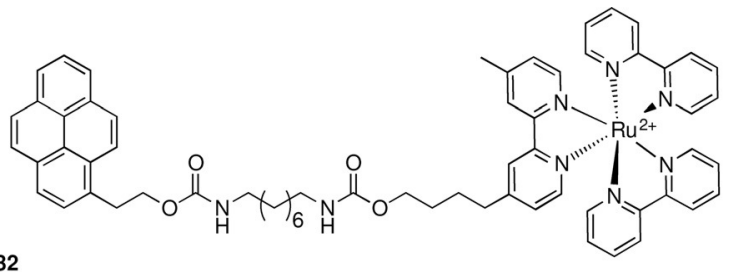

32
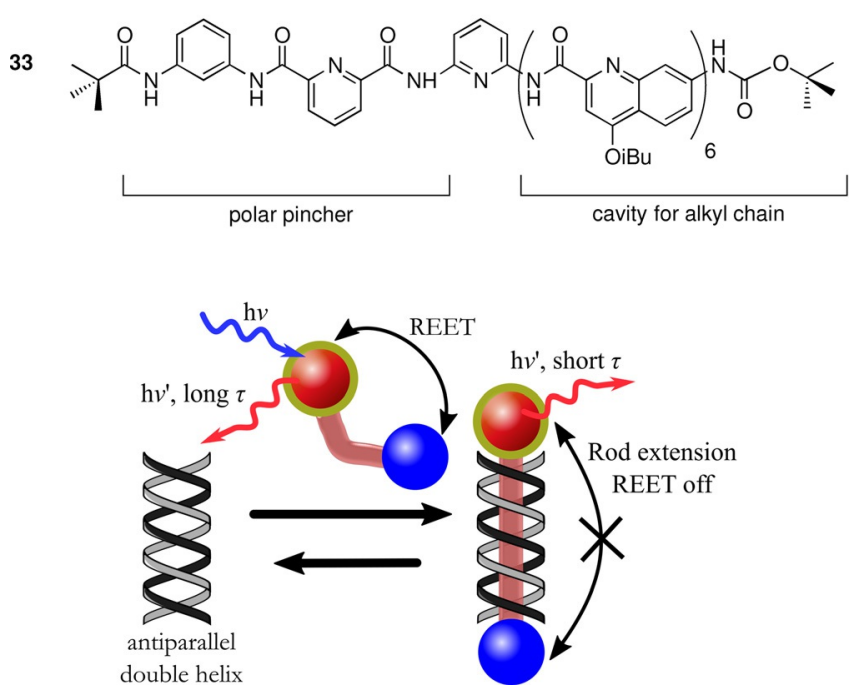

Figure 5. Top: Structural formulae of molecular thread (32) and foldamer (33), which dimerizes in solution giving (33) 2 . Bottom: Modulation of reversi ble electronic energy transfer in a dynamic foldaxane (right), a prototype lifetime based conformation probe.

From analysis of transient absorption spectra, namely the initial recovery of ground state bleaching to a metastable state, an equilibrium constant $K_{\text {eq }}=5$ could be determined.

In contrast, once incorporated into a foldaxane structure, where the central linear chain is extended, the interchromophore distance is prohibitive for efficient triplet-triplet energy transfer to occur. As a result, a decrease in luminescence lifetime approaching that of the parent $\mathrm{Ru}(\mathrm{bpy})_{3}{ }^{2+}$ would result. As the terminal chromophores may be considered bulky, interpenetration of the thread in the double helix cavity implies slow unfolding/ refolding of the double helix around the central thread.

Following mixing of a preformed double helix with the molecular thread association occurs, implicating hydrogen-bonding between the carbamate groups on the thread and the double helix $\left(K_{\text {ass }}=1700 \mathrm{M}^{-1}\right)$. A single-crystal X-ray structure of the assembly of ligand and double helix shows the long distance between terminals $(\geq 1.8 \mathrm{~nm})$. In an equilibrated mixture of thread $(60 \mu \mathrm{M})$ and double helix $(2 \mathrm{~mm})$, a lifetime of $1.2 \mu \mathrm{s}$ is observed, which is around half that of the free thread, showing that luminescence lifetime measurements can discriminate between the foldaxane and free components in this molecular machine. Real-time threading could be observed on plotting lifetime, average lifetime or pre-exponential factors against post-mixing time. A threading rate of $1.8 \mathrm{~min}^{-1} \mathrm{Lmol}^{-1}$ was thus estimated. As the luminescence lifetime is gradually shortening over the course of the threading experiment, it may be 
proposed that progressive elongation of the rod is occurring with stepwise unwinding/rewinding of the double helix allowing passage of the chromophore to the opposite aperture.

\section{Conclusions and Outlook}

REET can be used in matched bichromophoric systems, on paying particular attention to a few key parameters. Namely, the interchromophore distance should be appropriate to kinetically favour energy transfer, excited states should be sufficiently long-lived to allow interchromophore energy transfer and their low-lying excited states should be quasi-isoenergetic. A small but expanding range of transition metal complexes appended with appropriate organic chromophores have been shown to exhibit intramolecular REET. These complexes now include $\mathrm{Re}, \mathrm{Ru}, \mathrm{Cu}, \mathrm{Pt}$ and Ir metals, while chromophores include anthracene, pyrene, thiophenes, fluorene and BODIPY, amongst others. As well as application of conjugate dyads as photosensitizers, application of REET in molecular machines to signal conformation change/ assembly and promote pseudorotaxane disassembly has been demonstrated. Future molecular systems will no doubt focus on systems with higher emission quantum yield and emission in the near IR spectral region, as well as analyte-induced REET modulation. Then further applications in imaging in biological systems may be envisaged. Work is in progress in our laboratory to induce REET in nanomaterials, which may prove pertinent for molecular electronics and artificial photosynthesis using biomimetic multicomponent supramolecular arrays concurrently incorporating multiple photo- and electroactive units. Equally, REET in mechanically interlocked molecular structures will offer new functions as photosensitizers and in catalysis. Even beyond molecular machines, the conformational/ distance change resulting in a modified optical response may prove the general basis for a luminescence lifetime probe, which could report on a wealth of biological events and systems where even nanometric structural changes are possible. As it is based on Dexter rather than Förster energy transfer, the resulting probes can prove even more sensitive to interchromophore distance.

\section{Acknowledgements}

We are grateful for financial support from Labex Laphia, the University of Bordeaux, CNRS, China Scholarship Council (S.Y) and ANR FOSET (contract no. ANR-12-BS08-0007-01).

Keywords: foldaxanes - molecular machines - reversible electronic energy transfer • time-resolved spectroscopy • transition metal complexes

[1] a) A. Olaya Castro, G. D. Scholes, Int. Rev. Phys. Chem. 2011, 30, 4977 b) H. Q. Peng, L. Y. Niu, Y. Z. Chen, L. Z. Wu, C. H. Tung, Q. Z. Yang, Chem. Rev. 2015, 115, 7502 7542; c) H. E. Rajapakse, L. W. Miller, Proc Natl. Acad. Sci. USA 2010, 107, 13582 13587; d) V. K. Praveen, C. Ranjith, E. Bandini, A. Ajayaghosh, N. Armaroli, Chem. Soc. Rev. 2014, 43, 4222 4242.
[2] See for example, a) W. E. Ford, M. A. J. Rodgers, J. Phys. Chem. 1992, 96, 2917 2920; b) D. S. Tyson, F. N. Castellano, J. Phys. Chem. A 1999, 103, 1095510960 ; c) M. Hissler, A. Harriman, A. Khatyr, R. Ziessel, Chem. Eur. J. 1999, 5, 3366 3381; d) J. A. Simon, S. L. Curry, R. H. Schmehl, T. R. Schatz, P. Piotrowiak, X. Jin, R. P. Thummel, J. Am. Chem. Soc. 1997, 119, 1101211022 ; e) G. J. Wilson, A. Launikonis, W. H. F. Sasse, A. W. H. Mau, J. Phys. Chem. A 1998, 102, 51505156.

[3] a) X. Y. Wang, A. Del Guerzo, R. H. Schmehl, J. Photochem. Photobiol. C 2004, 5, 55 77; b) N. D. McClenaghan, Y. Leydet, B. Maubert, M. T. Indel li, S. Campagna, Coord. Chem. Rev. 2005, 249, 1336 1350; c) A. Lavie Cambot, C. Lincheneau, M. Cantuel, Y. Leydet, N. D. McClenaghan, Chem. Soc. Rev. 2010, 39, 506515.

[4] a) B. Maubert, N. D. McClenaghan, M. T. Indelli, S. Campagna, J. Phys. Chem. A 2003, 107, 447 455; b) J. Solarski, G. Angulo, A. Kapturkiewicz, J. Photochem. Photobiol. A 2011, 218, 58 63; c) J. Solarski, G. Angulo, A Kapturkiewicz, J. Photochem. Photobiol. A 2014, 274, 7382.

[5] a) N. D. McClenaghan, F. Barigelletti, B. Maubert, S. Campagna, Chem. Commun. 2002, 602 603; b) D. S. Tyson, K. B. Henbest, J. Bialecki, F. N. Castellano, J. Phys. Chem. A 2001, 105, 81548161.

[6] a) M. Montalti, A. Credi, L. Prodi, M. T. Gandolfi, J. W. Grate, G. C. Frye, Handbook of Photochemistry, 3rd ed., CRC/Taylor \& Francis, London, 2006; b) M. Rae, A. Fedorov, M. N. Berberan Santos, J. Chem. Phys. 2003, 119, 22232231.

[7] S. Campagna, F. Puntoriero, F. Nastasi, G. Bergamini, V. Balzani, in Top. Curr. Chem. Vol. 280, Springer, 2007, p. 117224.

[8] Y. Q. Fang, N. J. Taylor, F. Laverdière, G. S. Hanan, F. Loiseau, F. Nastasi, S. Campagna, H. Nierengarten, E. Leize Wagner, A. Van Dorsselaer, Inorg. Chem. 2007, 46, 28542863.

[9] R. Passalacqua, F. Loiseau, S. Campagna, Y. Q. Fang, G. S. Hanan, Angew. Chem. Int. Ed. 2003, 42, 1608 1611; Angew. Chem. 2003, 115, 1646 1649

[10] M. Abrahamsson, M. Jager, R. J. Kumar, T. Osterman, P. Persson, H. C. Becker, O. Johansson, L. Hammarström, J. Am. Chem. Soc. 2008, 130, 1553315542.

[11] G. Ragazzon, P. Verwilst, S. A. Denisov, A. Credi, G. Jonusauskas, N. D. McClenaghan, Chem. Commun. 2013, 49, 91109112.

[12] M. Jaeger, R. J. Kumar, H. Goerls, J. Bergquist, O. Johansson, Inorg. Chem. 2009, 48, 32283238.

[13] R. Siebert, C. Hunger, J. Guthmuller, F. Schlütter, A. Winter, U. S. Schu bert, L. González, B. Dietzek, J. Popp, J. Phys. Chem. C 2011, 115, 12677 12688.

[14] J. Fortage, G. Dupeyre, F. Tuyèras, V. Marvaud, P. Ochsenbein, I. Ciofini, M. Hromadová, L. Pospísil, A. Arrigo, E. Trovato, F. Puntoriero, P. P. Lainé, S. Campagna, Inorg. Chem. 2013, 52, 1194411955.

[15] T. A. Grusenmeyer, J. Chen, Y. Jin, J. Nguyen, J. J. Rack, R. H. Schmehl, J. Am. Chem. Soc. 2012, 134, 74977506.

[16] M. T. Indelli, M. Ghirotti, A. Prodi, C. Chiorboli, F. Scandola, N. D. McCle naghan, F. Puntoriero, S. Campagna, Inorg. Chem. 2003, 42, 54895497

[17] M. B. Majewski, N. R. de Tacconi, F. M. MacDonnell, M. O. Wolf, Inorg. Chem. 2011, 50, 99399941.

[18] S. Monro, J. Scott, A. Chouai, R. Lincoln, R. Zong, R. P. Thummel, S. A. McFarland, Inorg. Chem. 2010, 49, 28892900.

[19] R. Lincoln, L. Kohler, S. Monro, H. Yin, M. Stephenson, R. Zong, A. Chouai, C. Dorsey, R. Hennigar, R. P. Thummel, S. A. McFarland, J. Am. Chem. Soc. 2013, 135, 1716117175.

[20] M. Stephenson, C. Reichardt, M. Pinto, M. Wächtler, T. Sainuddin, G. Shi, H. Yin, S. Monro, E. Sampson, B. Dietzek, S. A. McFarland, J. Phys. Chem. A 2014, 118, 1050710521.

[21] S. Ji, W. Wu, W. Wu, H. Guo, J. Zhao, Angew. Chem. Int. Ed. 2011, 50, 1626 1629; Angew. Chem. 2011, 123, 16641667.

[22] a) R. R. Islangulov, D. V. Kozlov, F. N. Castellano, Chem. Commun. 2005, 37763778 ; b) T. N. Singh Rachford, F. N. Castellano, Coord. Chem. Rev. 2010, 254, 25602573.

[23] a) R. D. Costa, E. Orti, H. J. Bolink, F. Monti, G. Accorsi, N. Armaroli, Angew. Chem. Int. Ed. 2012, 51, 8178 8211; Angew. Chem. 2012, 124, 8300 8334; b) Y. You, W. Nam, Chem. Soc. Rev. 2012, 41, 7061 7084; c) M. S. Lowry, S. Bernhard, Chem. Eur. J. 2006, 12, 7970 7977; d) K. K. Lo, A. W. Choi, W. H. Law, Dalton Trans. 2012, 41, 6021 6047; e) L. Fla migni, A. Barbieri, C. Sabatini, B. Ventura, F. Barigelletti, Top. Curr. Chem. 2007, 281, p. 143203. 
[24] S. A. Denisov, Y. Cudré, P. Verwilst, G. Jonusauskas, M. Marín Suárez, J. F. Fernández Sánchez, E. Baranoff, N. D. McClenaghan, Inorg. Chem. 2014 53, 26772682.

[25] J. Howarth, D. L. Davies, F. Lelj, M. O. Wolf, B. O. Patrick, Inorg. Chem. 2014, 53, 1188211889.

[26] Q. Yan, Y. Fan, D. Zhao, Macromolecules 2012, 45, 133141.

[27] J. Peng, X. Jiang, X. Guo, D. Zhao, Y. Ma, Chem. Commun. 2014, 50, 78287830.

[28] B. W. Cohen, B. M. Lovaasen, C. K. Simpson, S. D. Cummings, R. F. Dallin ger, M. D. Hopkins, Inorg. Chem. 2010, 49, 57775779.

[29] M. T. Whited, P. I. Djurovich, S. T. Roberts, A. C. Durrell, C. W. Schlenker, S. E. Bradforth, M. E. Thompson, J. Am. Chem. Soc. 2011, 133, 8896

[30] T. Mani, D. M. Niedzwiedzki, S. A. Vinogradov, J. Phys. Chem. A 2012, 116,35983610

[31] F. N. Castellano, Dalton Trans. 2012, 41, 84938501.

[32] D. S. Tyson, C. R. Luman, X. Zhou, F. N. Castellano, Inorg. Chem. 2001, 40, 40634071.

[33] D. E. Polyansky, E. O. Danilov, F. N. Castellano, Inorg. Chem. 2006, 45, 23702372

[34] J. E. Yarnell, J. C. Deaton, C. E. McCusker, F. N. Castellano, Inorg. Chem. 2011, 50, 78207830.

[35] C. E. McCusker, A. Chakraborty, F. N. Castellano, J. Phys. Chem. A 2014 $118,1039110399$.

[36] L. Liu, S. Guo, J. Ma, K. Xu, J. Zhao, T. Zhang, Chem. Eur. J. 2014, 20, 1428214295.

[37] M. P. Gullo, J. B. Seneclauze, B. Ventura, A. Barbieri, R. Ziessel, Dalton Trans. 2013, 42, 1681816828.

[38] a) P. R. Ashton, V. Balzani, O. Kocian, L. Prodi, N. Spencer, J. F. Stoddart, J. Am. Chem. Soc. 1998, 120, 11190 11191; b) P. R. Ashton, R. Ballardini, V. Balzani, S. E. Boyd, A. Credi, M. T. Gandolfi, M. Gómez López, S. Iqbal, D. Philp, J. A. Preece, L. Prodi, H. G. Ricketts, J. F. Stoddart, M. S. Trolley, M.
Venturi, A. J. P. White, D. J. Williams, Chem. Eur. J. 1997, 3, 152 170; c) P. R. Ashton, R. Ballardini, V. Balzani, V. Balzani, E. C. Constable, A. Credi, O. Kocian, S. J. Langford, J. A. Preece, L. Prodi, E. R. Schofield, N. Spencer, J. F. Stoddart, S. Wenger, Chem. Eur. J. 1998, 4, 24132422.

[39] a) O. Johansen, A. W. H. Mau, W. H. F. Sasse, Chem. Phys. Lett. 1983, 94, 107112 ; b) O. Johansen, A. W. H. Mau, W. H. F. Sasse, Chem. Phys. Lett. 1983, 94, 113 117; c) J. Olmsted III, T. J. Meyer, J. Phys. Chem. 1987, 91, 1649 1655; d) C. Weinheimer, Y. Choi, T. Caldwell, P. Gresham, J. Olm sted III, J. Photochem. Photobiol. A 1994, 78, 119126.

[40] Y. Leydet, F. J. Romero Salguero, C. Jiménez Sanchidrián, D. M. Bassani, N. D. McClenaghan, Inorg. Chim. Acta 2007, 360, 987994.

[41] L. Scarpantonio, A. Tron, C. Destribats, P. Godard, N. D. McClenaghan, Chem. Commun. 2012, 48, 39813983.

[42] A. Rakhi, M. Arikkottira, K. Gopidas, R. Karical, Chem. Phys. Lett. 2015 618, 192197.

[43] Foldamers: Structure, Properties, and Applications (Eds.: S. Hecht, I. Huc), Wiley VCH, Weinheim, 2007.

[44] Y. Ferrand, Q. Gan, B. Kauffmann, H. Jiang, I. Huc, Angew. Chem. Int. Ed. 2011, 50, 7572 7575; Angew. Chem. 2011, 123, 77147717.

[45] S. A. Denisov, Q. Gan, X. Wang, L. Scarpantonio, Y. Ferrand, B. Kauff mann, G. Jonusauskas, I. Huc, N. D. McClenaghan, Angew. Chem. Int. Ed. 2016, 55, 1328 1333; Angew. Chem. 2016, 128, 13501355.

[46] a) J. Lakowicz, Principles of Fluorescence Spectroscopy, Kluwer Academic/ Plenum Publishers, New York, 1999; b) A. F. Morales, G. Accorsi, N. Ar maroli, F. Barigelletti, S. J. A. Pope, M. D. Ward, Inorg. Chem. 2002, 41, 67116719 